\title{
Australian Journal of Crop Science \\ Associations between pigments, antioxidant activity and coloring of blackberry fruits (Rubus sp.) and jellies through storage
}

\author{
Angela Vacaro de Souza*1, Fernando Ferrari Putti ${ }^{1}$, Marcos Ribeiro da Silva Vieira ${ }^{2}$, Rogério Lopes Vieites ${ }^{3}$
}

${ }^{1}$ São Paulo State University (Unesp), School of Science and Engineering, Tupã, SP, Brazil

${ }^{2}$ Federal University of Pará (UFPA), Altamira University Campus, Altamira, PA, Brazil

${ }^{3}$ São Paulo State University (Unesp), School of Agronomic Science, Botucatu, SP, Brazil

\section{*Corresponding author: angela.souza@unesp.br}

\begin{abstract}
The objective of this study was to investigate the relations between the amount of anthocyanins, carotenoids and the antioxidant activity measured by the FRAP and TEAC methods. Furthermore, pigments and the coloration of blackberry harvested fruits were measured at 3 different collection points then fruits stored in refrigerated environment and the jelly made from them, preserved in hermetically sealed glasses, without contact with light and temperature of $25 \circ \mathrm{C}$. In order to investigate the relations between the study variables (content of anthocyanins and carotenoids, antioxidant activity and coloration using digital colorimeter), Pearson's correlation analysis was adopted, which indicates the existence of a positive or negative relation between two variables. The $\alpha=5 \%$ (correlation coefficient) was used to verify the significance of the correlation. The Mahalanobis $\left(\mathrm{D}^{2}\right)$ generalized distance for the clustering analysis by the mean linkage method between group of blackberry fruits and jellies was applied. Furthermore, the cophenetic correlation coefficient and multivariate analysis using major components were applied to verify the grouping of different responses of harvesting points of fresh blackberry fruit in natura and jellies. The results showed that there was correlation between the content of anthocyanins and carotenoids in fruits $\left(0.99^{*}\right)$ and between the same parameters in jellies. However, this behavior was not clearly observed between the pigments and the antioxidant activity. There was a positive correlation between the factors involved in the coloring of chroma fruits ' $L$ ', ' $a$ ', ' $b$ ' and ㅇue in fruits and jellies. Blackberry jellies presented as good sources of anthocyanins and carotenoids.
\end{abstract}

Keywords: Rubus sp, food processing, postharvest, refrigerated storage, harvest point, multivariate analysis.

\section{Introduction}

Interest in small fruits has grown among consumers over the last few years because of growing studies about functional qualities, increased awareness of dietary practices, and the association of regular consumption of these fruits with better physical conditions related to their strong antioxidant properties (Oszmianski et al., 2015).

Blackberries (Rubus spp.) are notable for their antioxidant activities, particularly due to their high contents of polyphenolic compounds, such as ellagic acid, quercetin, gallic acid, anthocyanins, and cyanidins, plus excellent contents of the antioxidant vitamins A and C (Koca and Karadeniz, 2009). However, blackberries have a short market life and the fruit quality is rapidly reduced after harvesting (Joo and Lewandowski, 2011).

When destined for in natura consumption, maturation indices that include color, firmness, brightness and the pedicel's facility of detaching are important parameters to be evaluated at the time of harvest. Color is the main factor taken into account by the consumer when choose a food and so it is one of its most important characteristics. If the fruits are harvested before they develop purplish coloring, they are characterized by low sugars/organic acids ratio and unpleasant taste. The optimum harvest point for this type of fruit has not yet been established (Petkovsek et al., 2017). The blackberry has a bittersweet taste and high concentration of phenolic compounds. Among which the anthocyanic compounds are pigments that give a coloring that ranges from orange to red to blue. These stand out in human health, in the fight against neurodegenerative diseases, in the apoptosis of cancer cells, as antiinflammatory and antiproliferative, also possessing antioxidant function (Reátegui et al., 2014). In addition to anthocyanins, carotenoids also have antioxidant capacity, although they are present in low amounts in blackberry.

The efficiency of an antioxidant is dependent on its ability to hijack the free radicals (Sharma and Singh, 2013), and the phenolic compounds are responsible for the transfer of hydrogen that neutralizes the action of these radicals (Brewer, 2011). The economical utilization of non-standard fruits is a good alternative for producers to make jellies that are considered as the second product of commercial importance for the Brazilian fruit canning industry besides providing a greater supply and increase of shelf life (Santos et al., 2012). 
Principal component analysis (PCA) is a multivariate technique used to extract the important information from multivariate data (Voon et al., 2007). Partial least squares (PLS) and path analysis can be especially useful to fnd the correlations between intercorrelated quantitative dependent variables. Hence, application of a multivariate technique to characterize the relationship among the contente of pigments, the antioxidant activities, antioxidant enzymes activities, ROS levels, seems to be appropriate (Li et al., 2018). The objective of this study was to investigate the relationships between the amount of anthocyanins and carotenoids, the antioxidant activity by means of 2 determination methods and the coloration of blackberry fruits harvested at 3 different collection points and stored in a refrigerated environment and the jelly elaborated from the same ones.

\section{Results and Discussion}

\section{Correlation analysis by the Pearson method}

Table 1 shows the correlation analysis performed between anthocyanins, carotenoids and antioxidant activity by the methods already described. We observed the high degree of correlation between the content of anthocyanins and carotenoids in the fruits and between the same parameters in the jellies. The AA-FRAP method in fruits showed a negative correlation with the carotenoid content of the jellies, whereas the same method evaluated in the jellies showed a positive correlation only with the anthocyanins of the jellies. Anthocyanin is an unstable pigment, which can be degraded during processing, freezing and storage. Silva et al. (2011) evaluated the antioxidant capacity by the DPPH and ABTS method in blackberries of the same cultivar and other cultivars and other red fruits produced in the region of Rio Grande do Sul. According to these authors, there is a correlation between the content of anthocyanins and the value of antioxidant capacity of blackberry fruits by the methods tested. However, this behavior was not evidenced in this research.

Table 2 shows the positive correlation between the factors involved in the coloring of chroma fruits ' $L$ ', ' $a$ ', ' $b$ ' and 'Hue' in fruits and jellies. Chroma ' $a$ ' indicates the intensity of red to green (positive values are shades of red, and negative values, shades of green) but there was no evidence that anthocyanin content correlated directly with this parameter. In relation to the stability of anthocyanins, they are commonly found in the form of a mixture of different chemical structures in equilibrium: cation flavilium (red), quinoidal anhydrous base (blue), pseudobase carbitol (colorless) and chalcone (colorless or slightly yellow) (Lopes et al., 2007). This previously mentioned instability should influence the non-correlation between this content and the coloring of the fruits and jellies.

\section{Principal component analysis (PCA)}

The multivariate analysis was performed to verify the grouping of the different responses and to obtain additional information about the influence of the variables analyzed in relation to the samples of fruits and blackberry jellies analyzed over time (Figure 1). In this evaluation, we verified that components 1 and 2 (biochemical parameters and fruits and jellies, respectively) explained $64.54 \%$ of the behavior of the variables. However, it can be verified that there is a close approximation regarding to the content of anthocyanins and carotenoids present in the fruits, being the same phenomenon verified in relation to these two parameters in the jellies.

As observed in Table 1, there was no correlation between these compounds in fruits and jellies, showing that the processing may directly affect the contents of these compounds. The reduction of anthocyanin and carotenoid compounds throughout the storage time and due to processing may have occurred as a consequence of its oxidation, which reduces its concentration in the fruit (Yang et al., 2011). The stability in relation to the antioxidant activity can be explained by the formation of new compounds or increase in release of these phytochemicals, making them more accessible to extraction (Dewanto et al., 2002). However, the blackberry jelly retains a good amount of anthocyanins in the fruits and is a source to be considered of these compounds, since the contents present in this product are superior to those found in the in natura fruits of other red fruits (Cordenunsi et al., 2003).

Figure 2 shows that components 1 and 2 (pigments and coloring components in fruits and jellies, respectively) explained $74.34 \%$ of the behavior of the variables. The carotenoids and anthocyanins are mostly thermolabile and the main causes of color loss during storage and oxidation. The oxidation is accelerated by light, temperature and the presence of metallic catalysts (Sarantópoulos et al., 2001). In relation to the pigments and the coloring components, we noticed that the components of the coloring show an approximation in both fruits and jellies. Approximation also verified among the fruits and jellies of the treatment 3 and the same of the $15^{\text {th }}$ day of treatment 2 and the other fruits and jellies.

\section{Mahalanobis $\left(D^{2}\right)$ generalized distance for the clustering analysis}

The results presented in Figure 3 show that there is dissimilarity in relation to fruits and jellies of $T 1$, with the exception of products of day 0 (zero). The figure in question shows the dissimilarity of fruits and jellies in relation to the contents of anthocyanins and carotenoids analyzed and antioxidant activities. As the fruits undergo changes throughout the storage period and were harvested at different harvesting points, the dendrogram shows that there are no indications of well-evidenced dissimilarities. The same trend happened in jellies.

Regarding the pigments and parameters involved in the coloring, Figure 4 shows greater dissimilarities between the fruits during the storage period and the respective jellies. It can be verified that at the beginning of the study (time zero), the fruits present dissimilarity. The same occurs with day 3 and at lower levels throughout the storage period. As previously explained, the degradation of the pigments throughout the storage period and the modification of the coloring parameters may explain this phenomenon. 
Table 1. Correlation analysis between anthocyanins, carotenoids and antioxidant activity by FRAP and TEAC methods in fruits and blackberry jellies by the Pearson method.

\begin{tabular}{|c|c|c|c|c|c|c|c|c|}
\hline factors & $\begin{array}{l}\text { Anthoc. } \\
\text { fruits }\end{array}$ & $\begin{array}{l}\text { Carot. } \\
\text { fruits }\end{array}$ & $\begin{array}{c}\text { Anthoc. } \\
\text { jelly }\end{array}$ & $\begin{array}{c}\text { Carot. } \\
\text { jelly }\end{array}$ & $\begin{array}{l}\text { AA-FRAP } \\
\text { fruits }\end{array}$ & $\begin{array}{c}\text { AA-FRAP } \\
\text { jelly }\end{array}$ & $\begin{array}{c}\text { AA-TEAC } \\
\text { fruits }\end{array}$ & $\begin{array}{c}\text { AA-TEAC } \\
\text { jelly }\end{array}$ \\
\hline Anthoc. fruits & 1 & & & & & & & \\
\hline Carot. fruits & $0.99 *$ & 1 & & & & & & \\
\hline Anthoc. jelly & 0.03 & 0.02 & 1 & & & & & \\
\hline Carot. jelly & 0.21 & 0.20 & $0.70^{*}$ & 1 & & & & \\
\hline AA-FRAP fruits & -0.08 & -0.07 & -0.43 & $-0.53^{*}$ & 1 & & & \\
\hline AA-FRAP jelly & -0.01 & 0.00 & $0.57^{*}$ & 0.39 & -0.24 & 1 & & \\
\hline AA-TEAC fruits & -0.34 & -0.34 & -0.02 & -0.16 & $-0.61 *$ & -0.14 & 1 & \\
\hline AA-TEAC jelly & $0.54 *$ & $0.52 *$ & -0.31 & -0.21 & -0.04 & -0.45 & 0.05 & 1 \\
\hline
\end{tabular}

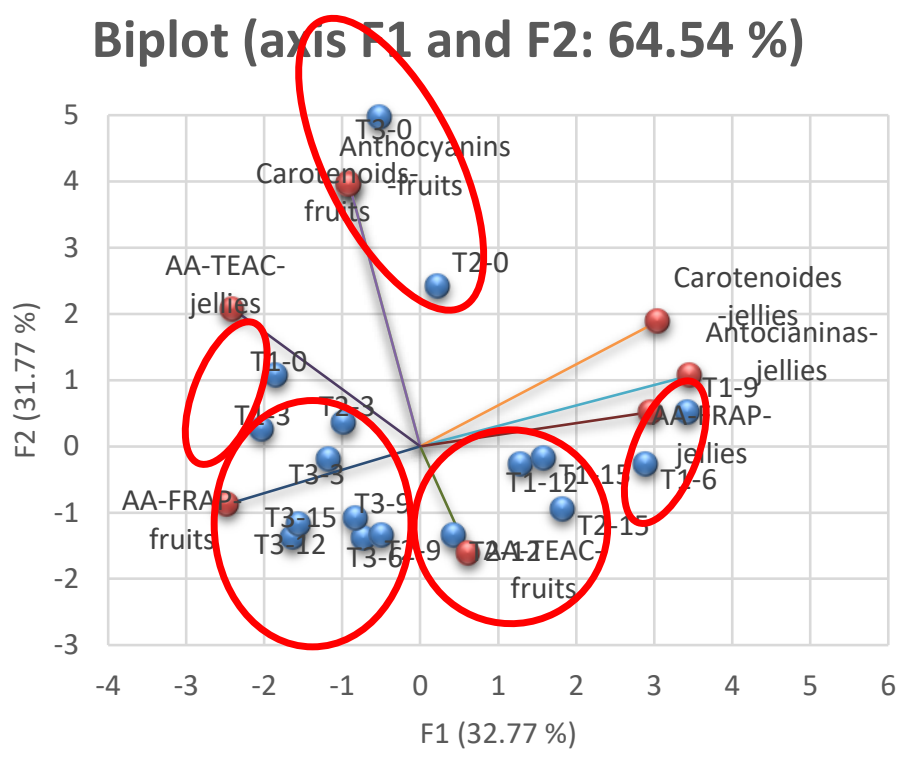

Fig 1. Analysis of major components of carotenoids, anthocyanins and antioxidant activity measured by the TEAC and FRAP methods in fruits and blackberry jellies throughout the storage period.

Table 2. Correlation analysis between anthocyanins, carotenoids and parameters involved with color ( $L, a, b$ and ohue) in fruits and blackberry jellies by the Pearson method.

\begin{tabular}{|c|c|c|c|c|c|c|c|c|c|c|c|c|}
\hline \multirow[b]{2}{*}{ Variables } & \multicolumn{6}{|c|}{ Fruits } & \multicolumn{6}{|c|}{ Jellies } \\
\hline & Anthoc. & Carot. & $\mathrm{L}$ & $a$ & $b$ & ohue & Anthoc. & Carot. & $\mathrm{b}$ & $a$ & $\mathrm{~L}$ & ohue \\
\hline Anthoc. fruits & 1 & & & & & & & & & & & \\
\hline Carot. fruits & $0.99 *$ & 1 & & & & & & & & & & \\
\hline$L$ fruits & 0.42 & 0.39 & 1 & & & & & & & & & \\
\hline a fruits & 0.11 & 0.08 & $0.90^{*}$ & 1 & & & & & & & & \\
\hline b fruits & 0.23 & 0.20 & $0.92 *$ & $0.96 *$ & 1 & & & & & & & \\
\hline ohue fruits & 0.28 & 0.25 & $0.55^{*}$ & $0.52 *$ & $0.66^{*}$ & 1 & & & & & & \\
\hline Anthoc. jelly & 0.03 & 0.02 & -0.41 & -0.45 & -0.44 & -0.08 & 1 & & & & & \\
\hline Carot. jelly & 0.21 & 0.20 & -0.22 & -0.44 & -0.39 & -0.13 & $0.70^{*}$ & 1 & & & & \\
\hline b jelly & 0.28 & 0.25 & $0.72 *$ & $0.77^{*}$ & $0.75^{*}$ & $0.50^{*}$ & -0.33 & -0.31 & 1 & & & \\
\hline a jelly & 0.24 & 0.20 & 0.74 & $0.79 *$ & $0.76 *$ & $0.49 *$ & -0.30 & -0.29 & $0.98 *$ & 1 & & \\
\hline L jelly & 0.07 & 0.03 & 0.70 & $0.78^{*}$ & $0.80 *$ & $0.51^{*}$ & -0.24 & -0.37 & 0.42 & 0.46 & 1 & \\
\hline ohue jelly & 0.30 & 0.28 & 0.76 & $0.83 *$ & $0.84 *$ & $0.56^{*}$ & $-0.55^{*}$ & $-0.56^{*}$ & $0.91 *$ & $0.88^{*}$ & $0.51 *$ & 1 \\
\hline
\end{tabular}




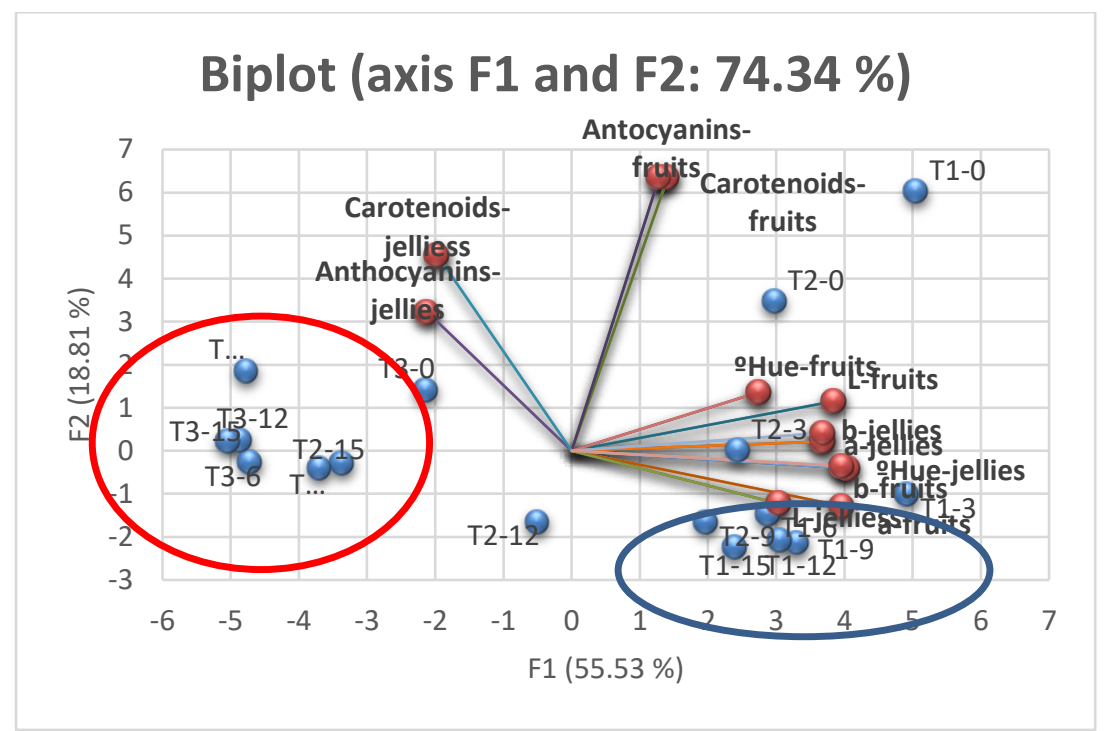

Fig 2. Analysis of major components of the content of carotenoids, anthocyanins and and coloring of berries and blackberry jellies over the storage period.

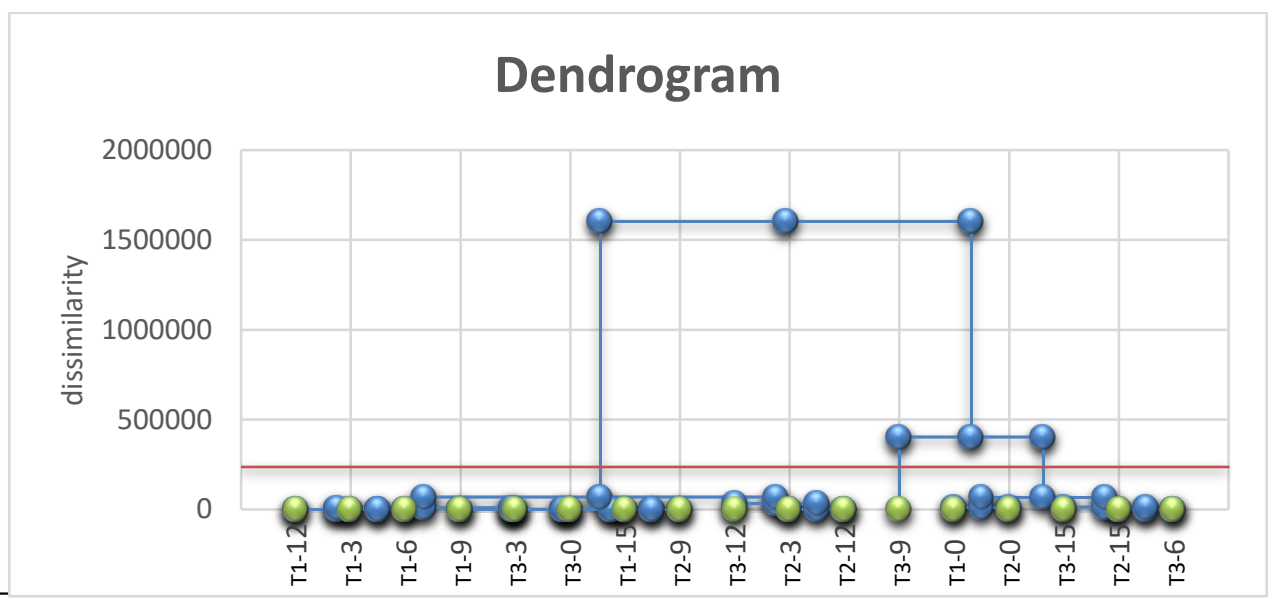

Fig 3. Dendrogram from the cluster analysis to classify fruits and blackberry jellies throughout the storage period as a function of the concentration of anthocyanins and carotenoids and antioxidant activity measured by the TEAC and FRAP methods.

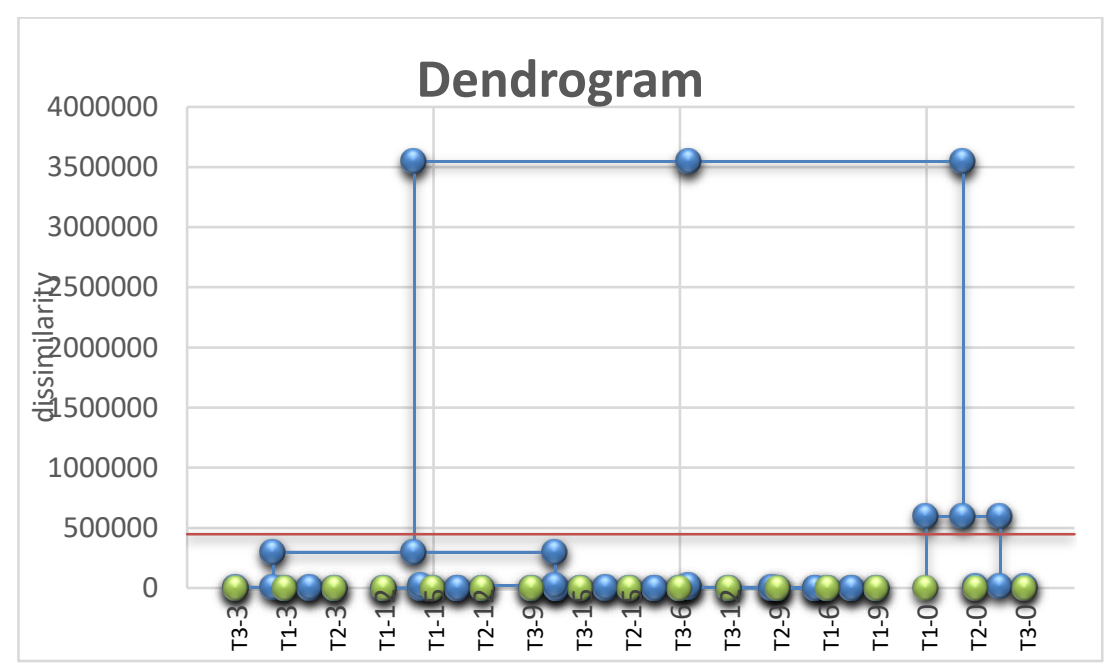

Fig 4. Dendrogram from the cluster analysis to classify blackberry fruits and jellies throughout the storage period as a function of the concentration of anthocyanins and carotenoids and coloration. 


\section{Materials and Methods}

\section{Plant material}

The blackberry fruits of 'Tupy' cultivar were harvested manually in the morning from a commercial orchard located in the municipality of Cerqueira César-SP (latitude $23^{\circ} 02^{\prime} 08^{\prime \prime}$ $\mathrm{S}$, longitude $49^{\circ} 09^{\prime} 58^{\prime \prime} \mathrm{W}$ and altitude of $737 \mathrm{~m}$ ) and transported immediately under refrigeration to the Fruit and Vegetable Laboratory of the Department of Horticulture of the Faculty of Agronomic Sciences of UNESP Botucatu Campus. Blackberries were washed in running water and immersed for 20 minutes in chlorinated solution at 20ppm and then exposed to air to dry naturally on clean and sanitized smooth surface benches. After drying the fruits, they were packed in polyethylene terephthalate trays (about $200 \mathrm{~g}$ ) with lid, and stored in a cold room at $5 \circ \mathrm{C}$ and $\mathrm{RH}$ $90 \% \pm 5$.

The collection points that constituted the treatments were defined visually, being: $100 \%$ red $-\mathrm{T} 1 ; 50 \%$ red and $50 \%$ black - T2 and $100 \%$ black - T3, the fruits were evaluated at the time of harvest (0) and at 3, 6, 9, 12 and 15 days after harvest and jellies elaborated from these fruits. It was decided to use this method because it is the most used by the producers.

\section{Processed Product}

For the manufacturing of jellies, the fruits were first pulped in a discontinuous stainless steel pulper with $0.5 \mathrm{~mm}$ mesh sieve and prepared with 50:50 (fruit: commercial crystal sugar). For the gelling, commercial pectin $(0.5 \%$ in relation to pulp weight) was used, and citric acid was not added due to the natural acidity of the fruits which verified in pre-tests. The cooking was carried out in open copper pot with a maximum capacity of $8 \mathrm{~L}$, with continuous manual stirring. The determination of the end point of the jelly was performed using a refractometer, with the value of 650BRIX being taken as standard. All the standards and methodologies for the elaboration of the jelly followed the Resolution $n^{\circ} 12$ of the CNNPA (Brazil, 1978). The jellies were stored in hermetically sealed glasses and protected from light at a temperature of $25^{\circ} \mathrm{C}$.

\section{Experimental design and biochemical analyses}

The evaluations of the jellies were carried out after 24 hours of the manufacturing so that there was stabilization coloring and other parameters. The extraction of the total carotenoids was carried out in fresh matter according to the method validated by Sims and Gamon (2002). The amount of material was adapted according to the properties of the plant, such as quantity and availability. The determination of the antioxidant activity was occurred in terms of oxidation inhibition potential using the 2.2-diphenyl-1-picrylhydrazyl radical (DPPH) as reference. The absorbance measurement at $517 \mathrm{~nm}$ was determined using a spectrophotometer (Singleton et al., 1999). The results were expressed as equivalent antioxidant capacity of TROLOX-TEAC (TEAC) in $\mu \mathrm{mol} \mathrm{g}^{-1}$ of sample according to standard curve (BrandWilliams et al., 1995). For the quantification of total antioxidant activity by the iron reduction method (FRAP), about $300 \mathrm{mg}$ of weighted fruit and jelly were used in $100 \mathrm{~mL}$ beaker with $40 \mathrm{~mL}$ of methanol at $50 \%$ and homogenized. The results were expressed in $\mu \mathrm{M}$ of ferrous sulfate $\mathrm{g}^{-1}$ of fruit. The coloring was performed with measuring in two points of each fruit and each jelly of each repetition using a Chroma meter colorimeter (brand Minolta CR300), expressed by the system with CIELAB scale. The coloration was expressed by the rectangular coordinate system $L^{*} a^{*}$ $b^{*}$ according to the CIE (Comission Internatinale de E'clairage), where $L^{*}$ expressed as percentage of luminosity values $(0 \%=$ black and $100 \%=$ white $), a^{*}$ represents the colors red $(+)$ or green $(-), b^{*}$ yellow $(+)$ or blue $(-)$ colors and oHue. This was calculated using the formula ${ }^{\circ}$ Hue $=\tan$ $1 \mathrm{~b} * / \mathrm{a} *$. The ofue has variation of: 0 to $12^{\circ}$ for the red coloration, 13 to 41 의 for the orange coloration, 42 to 69 o for the yellow coloration, 70 to 166 o for green, 167 to 251 ㅇ for blue, 252 to 305 o for violet and 306 to 359 o for red, making 360 ‥ At the study, they will be treated as chroma ' $L$ ', ' $a$ ', ' $b$ ' and color angle (ㅇue).

\section{Statistical analysis}

In order to investigate the relations between the variables of the study, Pearson's correlation analysis was used, which indicates the existence of a positive or negative relation between two variables, with $\alpha=5 \%$ (correlation coefficient) being used to verify the significance. The analyzes were performed with the software Statistica and Sigmaplot. To better understand the results, the data were grouped to compare and correlate the anthocyanin and carotenoid pigments in the fruits and jellies. The antioxidant activity was measured by FRAP and TEAC methods and the anthocyanin and carotenoid pigments with the parameters involved with the coloration (chroma ' $L$ ', ' $a$ ', ' $b$ ' and oHue) in fruits and jellies.

The general distance of Mahalanobis $\left(D^{2}\right)$ was determined for the clustering analysis of blackberry fruits and jellies, by the mean linkage between group (UPGM) method. After it was determined, the cophenetic correlation coefficient (CCC) enabled the adjustment between the dissimilarity matrix and the dendrogram obtained (Cruz et al., 2014, Souza et al., 2018).

A multivariate analysis was carried out by main components (PCA) to verify the grouping of the different responses of harvesting points of fresh blackberry fruits in natura and the jellies elaborated from them during the storage period, having variables of biochemical characteristics (anthocyanins, carotenoids, antioxidant activity through 2 different methods) and coloring (chroma ' $\mathrm{L}$ ', ' $a$ ', ' $b$ ' and oHue), simulating the relations between these variables (Vitolo et al., 2012). In order to perform the analysis, the Statistica software was used using the minimum absorption criteria of $80 \%$ in the first two main components to simulate a possible relation between the variables (Cruz et al., 2014).

\section{Conclusion}

We concluded that there is a correlation between the evaluated pigments and antioxidant activity, depending on the methods used. There was a strong approximation regarding the dissimilarity analysis when we evaluated the amount of anthocyanins and carotenoids and the coloration of the fruits and jellies showing a relation between these parameters. 
Another important conclusion is that blackberry jelly keeps significant amount of anthocyanins and carotenoids during the processing of fruits and; therefore, are important source to be considered for these compounds.

\section{References}

Brand-Williams W, Cuvelier ME, Berset C (1995) Use of free radical method to evaluate antioxidant activity. Food Sci and Tech. 28: 2530.

Brasil. Ministério da Saúde. Secretaria de Vigilância Sanitária. (1978) Resolução Normativa no. 15 de 4 de maio de 1978. Define termos sobre geleia de frutas.

Brewer MS (2011) Natural antioxidants: sources, compounds, mechanisms of action, and potential applications. Comprehensive Reviews Food Sci Food Saf. 10:221-247.

Cordenunsi BR, Nascimento JRO, Lajolo FM (2003) Physicochemical changes related to quality of five strawberry fruit cultivars during cool-storage. Food Chem, 83: 167-173.

Cruz CD, Regazzi AJ, Carneiro PCS (2014) Divergência genética. In: Cruz CD, Regazzi AJ, Carneiro PCS (Ed). Modelos biométricos aplicados ao melhoramento genético. 3rd edn UFV, Viçosa. 2.

Dewanto V, Wu X, Adom KK, Liu ARH (2002) Thermal processing enhances the nutritional value of tomatoes by increasing total antioxidant activity. J Agric Food Chem. 50:3010-3014.

Joo M, Lewandowski N, Auras R, Harte J, Almenar, N (2011) Comparative shelf life study of blackberry fruit in biobased and petroleum-based containers under retail storage conditions. Food Chem. 126:1734-1740. 4.

Koca, I, Karadeniz B (2009) Antioxidant properties of blackberry and blueberry fruits grown in the black sea region of Turkey, Scientia Horticulturae. 121: 447-450. 4.

Li J, Ma G, Ma L, Bao X, Li L, Zhao Q, Wang Y. (2018) Multivariate analysis of fruit antioxidant activities of blackberry treated with 1-methylcyclopropene or vacuum precooling. Intern J Anal Chem. 2416461. PMID 29487622 DOI: $10.1155 / 2018 / 2416461$

Lopes TJ, Xavier MF, Quadri MGN, Quadri, MB (2007) Antocianinas: uma breve revisão das características estruturais e da estabilidade. R. Bras. Agroc, Pelotas,13:291-297. 3.

Santos PRG (2012) Geleia de cagaita (Eugenia dysenterica DC.); Desenvolvimento, caracterização microbiológica, sensorial, química e estudo da estabilidade. Revista do Inst Adolfo Lutz.71. 2.
Sharma P, Singh RP (2013) Evaluation of antioxidant activity in foods with special reference to TEAC method. Am J o Food Tech. 8: 83-101.

Sarantópoulos CIGL, Oliveira LM, Canavesi E (2001). Alterações de alimentos que resultam em perda de qualidade. In: Sarantópoulos, CIGL, Oliveira, LM, Canavesi E. Requisitos de conservação de alimentos em embalagens flexíveis. Campinas: CETEA/ITA, 1:1-22.

Oszmianski J, Nowicka P, Teleszko M, Wojdylo A, Cebulak T, Oklejewicz K. (2015) Analysis of phenolic compounds and antioxidant activity in wild blackberry fruits. Intern J Molec Sci. 16:14540-14553.

Petkovsek MM, Koron D, Zorenc Z, Veberic R (2017) Do optimally ripe blackberries contain the highest levels of metabolites? Food Chem. 215: 41-49. 15.

Reátegui JLP, Machado APF, Barbero GG, Rezende CA, Martínez J (2014) Extraction of antioxidant compounds from blackberry (Rubus sp) bagasse using supercritical $\mathrm{CO} 2$ assisted by ultrasound. The J of Supercritical Fluids, Blacksburg. 94: 223-233.

Silva RS, Vendruscolo JL, Toralles RP (2011) Avaliação da capacidade antioxidante em frutas produzidas na região sul do RS. Rev Bras de Agroc. Pelotas, 17: 392-400. 3-4.

Sims DA, Gamon JA (2002) Relationships between leaf pigment content and spectral reflectance across a wide range of species, leaf structures and developmental stages. Remote Sensing of Environment. 81:337-354.

Singleton VL, Orthofer R, Lamuela RM (1999) Analysis of total phenol and other oxidation subtrates and antioxidants by means of Folin-Ciocauteau reagent. Meth Enzymology.299:152-178.

Souza AV, Vieira MRS, Putti FF (2018) Correlações entre compostos fenólicos e atividade antioxidante em casca e polpa de variedades de uva de mesa. Braz J Food Tech. 21.

Vítolo HF, Souza GM, Silveira J. (2012) Cross-scale multivariate analysis of physiological responses to high temperature in two tropical crops with C3 and C4 metabolism. Environm Experim Botany. 80. 1.

Voon YY, Sheikh N, Abdul Hamid, Rusul G, Osman A, Quek SY (2007) Volatile favour compounds and sensory properties of minimally processed durian (Durio zibethinus cv. D24) fruit during storage at $4 \circ \mathrm{C}$, Postharvest Biol Tech. 46:7685. 1.

Yang Y, Wang J, Xing Z, Dai Y, Chen M (2011) Identification of phenolics in Chinese toon and analysis of their content changes during storage. Food Chem. 128:831-838. 